9. Dodge. H. T., Sandler, H., Baxley, W. A., and Hawley, R. R.: Usefulness and limitations of radiographic method for determining left ventricular volume. Amer. J. Cardiol., 18: 10 (1966)

10. Flamm, M. D.. Cohn, K. E., and Hancock, E. W.: Ventricular function in atrial septal defect. Amer. J. Med. 48: 286 (1970).

II. Garrard, C. L., Jr.. Weissler, A. M., and Dodge, H. T.: The relationship of alterations in systolic time intervals to ejection fraction in patients with cardiac disease. Circulation, 42: 455 (1970).

12. Golde, D., and Burstin. L.: Systolic phases of the cardiac cycle in children. Circulation, 42: 1029 (1970)

13. Graham, T. P., Jr., Jarmakani, J. M., and Canent, R. V., Jr.: Left heart volume characteristics with a right ventricular volume overload: Total anomalous pulmonary venous connection and large atrial septal defect. Circulation, 45 389 (1972)

14. Graham, T. P., Jarmakani, M. M., Canent, R. V.. Capp, M. P.. and Spach, M. S.: Characterization of left heart volume and mass in normal children and infants with intrinsic myocardial disease. Circulation, 38: 826 (1968).

15. Graham, T. P., Jr., Jarmakani, J. M., Canent, R. V., Jr., and Morrow, M. N. Left heart volume estimation in infancy and childhood: Re-evaluation of methodology and normal values. Circulation, 43: 895 (1971).

16. Hermann, H. J., and Bartle, S. H.: Left ventricular volumes by angiocardiography: comparison of methods and simplification of techniques. Cardiovasc. Res., 4: 404 (1968).

17. Hodges, M.. Halpern, B. L., Friesinger, G. C., and Dagenais, G. R.: Left ventricular pre-ejection period and ejection time in patients with acute myocardial infarction. Circulation, 45: 933 (1972).

18. Judge, T. P., Kennedy, J. W.. Bennet, L. J., Wills, R. E., Murray, J. A., and Blackman, J. R.: Quantitative hemodynamic effects of heart rate in aortic regurgitation. Circulation, 44: 355 (1971).

19. Kelly, D. T. Spotnitz, H. M.. Beiser, G. D.. Pierce, J. E., and Epstein, S. E. Effect of chronic right ventricular volume and pressure loading on left ventricular performance. Circulation, 44: 403 (1971).

20. Kennedy, J. W., Baxley, W. A., Figley, M. M., Dodge, H. T., and Blackman, J. R.: Quantitative angiocardiography. 1. The normal left ventricle in man. Circulation, 34: 272 (1966)

21. Levinson, G. E., Frank, M. J., Nadimi, M., and Braunstein, M.: Studies of cardiopulmonary blood volume: measurement of left ventricular volume by dye dilution. Circulation, 35: 1038 (1967).

22. Lewis, R. P., Boudoulas, H., Forester, W. F., and Weissler, A. M.: Shortening of electromechanical systole as a manifestation of excessive adrenergic stimulation in acute myocardial infarction. Circulation, 46: 856 (1972).
23. Martin. C. E.. Shaver, J. A., Thompson, M. E., Reddy, P. S., and Leonard, J J. Direct correlation of external systolic time intervals with internal indices of left ventricular function in man. Circulation. 44: 419 (1971).

24. Michelson, N.: Bilateral ventricular hypertrophy due to chronic pulmonary disease. Dis. Chest, 38: 435 (1960)

25. Miller, G. A. H. Kirklin, J W. Rahimtoola, S. H and Swan, H. J. C.: Volume of the left ventricle in tetralogy of Fallot. Amer. J. Cardiol.. 16: 488 (1965).

26. Mirsky. I., Pasternac, A., and Ellison, R. C.: General index for the assessment of cardiac function. Amer. J. Cardiol., 30: 483 (1972).

27. Nadas, A. S. and Fyler. D. C.: Pediatric Cardiology, Ed. 3 (W. B. Saunders. Philadelphia, 1972)

28. Rotem, C. E., and Miller. H.: Diagnostic applications of the platinum electrode catheter. Brit. Heart J., 29: 232 (1967)

29 Rudoloh, A, M. and Cayler, G. G. Cardiac catheterization in infants and children. Pediat. Clin. N. Amer. 5: 907 (1958).

30. Weissler, A. M., Harris, W. S., and Schoenfeld, C. D.: Bedside technique for the evaluation of ventricular function in man. Amer. J. Cardiol. 23: 577 (1969).

31. Weissler A M. Peeler. R. G. and Roehll, W H. Relationship between lef ventricular ejection time, stroke volume, and heart rate in normal individuals and patients with cardiovascular disease. Amer. Heart J., 62: 367 (1961)

32. Weissler, A. M. and Schoenfeld, C. D.: Effect of digitalis on systolic time intervals in heart failure. Amer., J. Med. Sci.. 259: 4 (1970).

33. Wood. E. H.: Diagnostic applications of indicator-dilution technics in congenital heart disease. In: Sympsoium on Dye Dilution Techniques. Circ. Res. 10:531 (1962).

34. Cook Co., Inc.

35. Winthrop Laboratories, New York, N. Y

36. Siemens Corp., Iselin, N. J.

37. The authors wish to express their appreciation to Miss Barbara Belfer (New York Hospital-Cornell Medical Center) for her assistance in the accumulation of data and to Mrs. Linda Tartell, Mrs. Shirley Williams, and Mrs. Alice Kramer for their secretarial assistance.

38. Dr. Liebson's present address: Cardiology Division, Rush-Presbyterian-St Luke's Medical Center, Chicago, III

39. Dr. Diamant is deceased.

40. This research was presented in part before the American Academy of Pediatrics October 15, 1972

41. Requests for reprints should be addressed to: Aaron R, Levin, M.D., Pediatric Cardiac Catheterization Laboratory. The New York Hospital-Cornell Medical Center, 525 E. 68 St. New York, N. Y. 10021 (USA)

42. Accepted for publication July 17, 1975
Biopterin

dithioerythritol

hyperphenylalaninemia lysolecithin

phenylalanine hydroxylase

phenylketonuria

\title{
Determination of Phenylalanine Hydroxylase Activity in Patients with Phenylketonuria and Hyperphenylalaninemia
}

\author{
K. BARTHOLOME, (21) P. LUTZ, AND H. BICKEL \\ University Children's Hospital, Heidelberg, Federal Republic of Germany
}

\section{Extract}

The phenylalanine hydroxylase assay was modified by using biopterin, lysolecithin, and dithioerythritol. Liver tissue was obtained by percutaneous needle biopsies in patients with phenylketonuria (PKU) and hyperphenylalaninemia. The use of the naturally occurring cofactor biopterin is essential to measure low enzyme activities. Thirteen of 14 assay specimens in which no activity was detectable correlated with the clinical picture of classic PKU. Twelve assay specimens showed a residual activity up to $6 \%$ of normal. This group comprises patients with classic PKU and with so-called hyperphenylalaninemia. Four specimens ranged between
8.7 and $34.5 \%$ of the normal values. Patients in this group have developed normally so far without dietary treatment. It seems that patients with residual activity tolerate more phenylalanine in the diet than patients with no detectable activity. One infant with biochemical symptoms of classic PKU was found to have a normal phenylalanine hydroxylase activity.

\section{Speculation}

The variety of enzyme activities may reflect individual defects within the enzyme molecule. The clinical picture of PKU may not necessarily involve a defect of the phenylalanine hydroxylase in each 
case. The determination of the phenylalanine hydroxylase activity together with the biochemical parameters hitherto used might contribute to the differential diagnosis of PKU-hyperphenylalaninemia.

Phenylalanine hydroxylase (EC. 1.14.3.1) was first shown to be deficient in patients with PKU by Udenfriend and Cooper (16), and this was confirmed by Jervis (7). The complexity of the phenylalanine hydroxylation system was elucidated mainly by Kaufman (10) and by La Du and Zannoni (13).

Classic PKU (18) requires early dietary treatment to prevent mental retardation. Hyperphenylalaninemia, a condition which simulates PKU biochemically, is believed by most authors not to cause retardation or to need therapy. The differential diagnosis and decision regarding treatment are based on biochemical parameters, some of which are still ambiguous. An additional parameter of diagnostic value might be the determination of phenylalanine hydroxylase. So far only a few reports are available in which enzyme activity was measured in PKU and variant patients $(6,8,9)$.

\section{MATERIALS AND METHODS}

Liver needle biopsies were kindly performed by Dr. D. Feist. The tissue (10-30 mg) was frozen immediately in liquid nitrogen and kept frozen at $-70^{\circ}$ for $1-4$ weeks before use. L-Phenylalanine was purchased from Merck, Germany, ${ }^{14} \mathrm{C}$-labeled Lphenylalanine from New England Nuclear Co., lysolecithin was obtained from K. Roth, Germany, and dithioerythritol from Serva, Germany. Tetrahydrobiopterin was generously given to us by Professor Pfleiderer, Konstanz, Germany.

\section{PHENYLALANINE HYDROXYLASE ASSAY}

The extraction was performed in $0.15 \mathrm{M} \mathrm{KCl}(1: 20 \mathrm{w} / \mathrm{v})$ using a Branson Sonifier. The tissue was in a plastic Eppendorf tube, which was immersed in an ice-salt mixture. The sonication time was $2 \mathrm{sec}$ with an interval of $1 \mathrm{~min}$, the procedure being repeated five times. The homogenate was transferred to a polyethylene centrifuge tube and centrifuged for $30 \mathrm{~min}$ at $40000 \times \mathrm{g}$ in a Beckman centrifuge with a SW 65 head; the supernatant fluid was used in the assay. The standard assay mixture contained $0.15 \mathrm{M}$ sodium-potassium phosphate ( $\mathrm{pH}$ 6.9), $2 \mathrm{mM}$ dithioerythritol, $0.1 \mathrm{mM}$ 1-phenylalanine, $0.2 \mu \mathrm{Ci}\left[{ }^{14} \mathrm{C}\right]$ phenylalanine, $1 \mathrm{mM}$ lysolecithin, $0.025 \mathrm{mM}$ tetrahydrobiopterin (dissolved in ice-cold $0.005 \mathrm{~N} \mathrm{HCl}$ and stored frozen), varying amounts of liver extract up to $0.04 \mathrm{ml}$, and water up to a final volume of $0.2 \mathrm{ml}$.

The reaction was started with tetrahydrobiopterin as the last component added. One tube contained the complete reaction mixture but with extract which had been boiled before. The mixture was incubated at $25^{\circ}$ in a shaking water bath. The reaction was stopped by the addition of $3 \mathrm{M}$ perchloric acid $(1: 4, v / v)$. The tubes were then placed in an ice bath for $5 \mathrm{~min}$ and centrifuged afterwards.

Aliquots $(0.01 \mathrm{ml})$ of the deproteinized supernatant were applied under a stream of cold air to a cellulose thin layer plate. Tyrosine and phenylalanine standards were spotted on top of each aliquot. The plates were developed for $20 \mathrm{~min}$ at room temperature in $\mathrm{CHCl}_{3}-\mathrm{CH}_{3} \mathrm{OH}-\mathrm{NH}_{4} \mathrm{OH}-\mathrm{H}_{2} \mathrm{O}(58: 32: 8: 2, \mathrm{v} / \mathrm{v})$ (15). After drying in air, the plates were sprayed with a ninhydrin solution. Each plate was scanned, then the areas in which radioactivity was found were scratched off with a razor blade and put in a vial. First $1 \mathrm{ml}$ water, then $4 \mathrm{ml}$ Unisolve (17) were added. The radioactivity was determined in a liquid scintillation counter.

\section{CALCULATION OF TYROSINE FORMED}

The ratio of counts of tyrosine to tyrosine plus phenylalanine was determined and corrected for the counts of boiled enzyme; by multiplication by the phenylalanine input $(0.02 \mu \mathrm{mol} / \mathrm{assay})$ the moles of tyrosine formed per unit time were calculated. This figure was related to the protein content. Protein was determined as described by Lowry (14).

The samples from persons who served as control subjects were gained either during laparatomies performed with cholecystectomy or from needle biopsies performed in children with nonmetabolic liver diseases.

\section{RESULTS}

Figure 1 shows the interrelation between tyrosine formation and reaction time. Linearity is found up to approximately $20 \mathrm{~min}$ depending on the enzyme concentration, which indicates a substrate limitation. Figure 2 illustrates tyrosine formation when the naturally occurring cofactor, biopterin, was used instead of dimethylpteridine. Biopterin provides optimal conditions in the assay for low residual activities. The use of biopterin implicates the addition of lysolecithin (5). Preincubation of the enzyme with lysolecithin results in a hyperbolic shape of the time kinetic curve. Therefore, the simultaneous addition is preferred to avoid this burst.

In Table 1 all phenylalanine hydroxylase determinations are listed. Our results can be subdivided in three major groups as shown in Figure 3: $(A)$ activity not detectable, $(B)$ reduced activity, (C) normal activity.

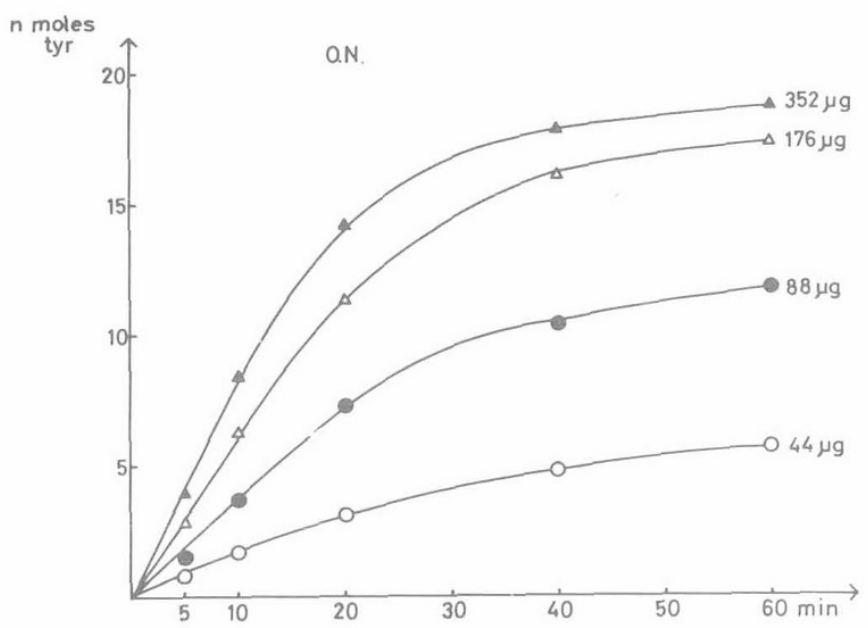

Fig. 1. Interrelation between the amount of tyrosine $(t y r)$ formed and reaction time at varying enzyme concentrations in the assay (abscissa) on a control subject. Substrate input: $20 \mathrm{nmol}$ phenylalanine.

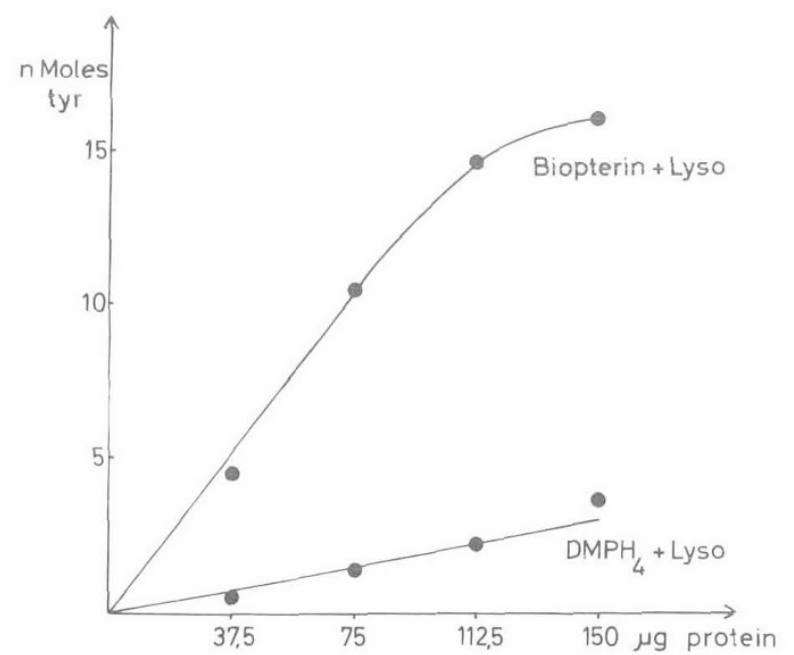

Fig. 2. Comparison of tyrosine (tyr) formation with the natural cofactor biopterin and the synthetic cofactor dimethylpteridine $\left(\mathrm{DMPH}_{4}\right)$ at varying enzyme concentrations (abscissa). Lyso: lysolecithin. 
Table 1. Phenylalanine hydroxylase values in control subjects (cases 1-13), in patients with hyperphenylalaninemia (cases 14-30), and in phenylketonuria (cases 3I-43)

\begin{tabular}{|c|c|c|c|c|c|}
\hline $\begin{array}{l}\text { Current } \\
\text { case no. }\end{array}$ & Subject & Age, yr & Sex & $\begin{array}{c}\mu \mathrm{mol} \\
\text { tyrosine } / \mathrm{g} \\
\text { protein } \\
\times 60 \mathrm{~min}\end{array}$ & $\begin{array}{c}\% \text { of } \\
\text { average } \\
\text { from control } \\
\text { subjects }\end{array}$ \\
\hline 1 & $K B$ & 70 & f & 81.7 & 87.4 \\
\hline 2 & $E M$ & 40 & f & 83.7 & 88.9 \\
\hline 3 & $B M$ & 12 & $\mathrm{~m}$ & 63.6 & 68.1 \\
\hline 4 & $E C$ & 2 & $\mathrm{~m}$ & 134.0 & 143.3 \\
\hline 5 & $J V$ & 4 & $\mathrm{~m}$ & 69.7 & 74.6 \\
\hline 6 & KO & 55 & f & 87.4 & 93.5 \\
\hline 7 & $J H$ & 46 & $\mathrm{~m}$ & 79.8 & 85.4 \\
\hline 8 & $W S$ & 7 & $\mathrm{~m}$ & 120.4 & 128.8 \\
\hline 9 & $P E$ & 38 & $\mathrm{~m}$ & 86.8 & 92.9 \\
\hline 10 & $R M$ & 60 & f & 102.0 & 109.2 \\
\hline 11 & $O B$ & 40 & f & 90.9 & 97.2 \\
\hline 12 & $W R$ & 14 & $\mathrm{~m}$ & 105.9 & 113.4 \\
\hline 13 & $S M$ & 12 & $f$ & 109.1 & 116.7 \\
\hline 14 & BJ & 19 & $\mathrm{~m}$ & 4.6 & 5.0 \\
\hline 15 & $W P$ & 14 & $\mathrm{~m}$ & 2.8 & 3.0 \\
\hline 16 & $K T$ & 1 & f & 5.8 & 6.2 \\
\hline 17 & $F B$ & 4 & f & 2.3 & 2.4 \\
\hline 18 & $G E$ & 4 & $\mathrm{~m}$ & 1.7 & 1.8 \\
\hline 19 & $B A$ & 10 & $\mathrm{~m}$ & 2.2 & 2.3 \\
\hline 20 & $W M$ & 5 & $\mathrm{~m}$ & 1.4 & 1.5 \\
\hline 21 & $F G$ & 1 & $\mathrm{~m}$ & 3.0 & 3.2 \\
\hline 22 & $T A$ & $4 / 12^{\circ}$ & f & 2.0 & 2.2 \\
\hline 23 & $M A$ & $6 / 12$ & f & 2.2 & 2.4 \\
\hline 24 & $M T$ & 7 & $\mathrm{~m}$ & 2.1 & 2.2 \\
\hline 25 & $A S$ & $1 / 12$ & $\mathrm{~m}$ & 2.0 & 2.2 \\
\hline 26 & $M K$ & $6 \mathrm{wk} / 4 / 12$ & $\mathrm{~m}$ & $75.5 / 55.2$ & $80.8 / 59.1$ \\
\hline 27 & $N M$ & 2 & f & 13.9 & 14.9 \\
\hline 28 & $D A$ & 3 & $\mathrm{~m}$ & 29.7 & 31.8 \\
\hline 29 & $K M$ & 1 & $\mathrm{~m}$ & 32.2 & 34.5 \\
\hline 30 & $N M$ & 4 & $\mathrm{~m}$ & 8.1 & 8.7 \\
\hline 31 & $Z F$ & 8 & $\mathrm{~m}$ & 0 & 0 \\
\hline 32 & $S M$ & $1 / 12$ & f & 0 & 0 \\
\hline 33 & $C A$ & $3 / 12$ & $\mathrm{~m}$ & 0 & 0 \\
\hline 34 & $B D$ & 3 & $\mathrm{~m}$ & 0 & 0 \\
\hline 35 & $S A$ & 4 & $\mathrm{~m}$ & 0 & 0 \\
\hline 36 & $K E$ & 1 & $f$ & 0 & 0 \\
\hline 37 & $S G$ & 1 & $\mathrm{~m}$ & 0 & 0 \\
\hline 38 & $H S$ & 3 & $f$ & 0 & 0 \\
\hline 39 & $D S$ & 3 & f & 0 & 0 \\
\hline 40 & $E F$ & 2 & $\mathrm{~m}$ & 0 & 0 \\
\hline 41 & $Z C$ & 1 & $\mathrm{f}$ & 0 & 0 \\
\hline 42 & $S A$ & 9 & $\mathrm{~m}$ & 0 & 0 \\
\hline 43 & $K O$ & 7 & $\mathrm{~m}$ & 0 & 0 \\
\hline
\end{tabular}

Correlating the enzyme activity to the clinical picture, of the patients with no detectable activity (group $A$ ), all but one (see below) suffered from classic PKU in their clinical and biochemical parameters; if untreated, they were mentally retarded (except case 33; Table 1). Group B with reduced activity covers a broad range from 0.8 and $31 \mu \mathrm{mol}$ tyrosine $/ \mathrm{g}$ protein $\times 60 \mathrm{~min}$; the group is apparently heterogeneous. Twelve cases exhibited enzyme activities below $6 \mu \mathrm{mol}$ tyrosine $/ \mathrm{g}$ protein $\times 60 \mathrm{~min}$. Of these 12 cases 3 are seriously retarded patients (cases 14, 15, 17; Table 1). Two of them have siblings (cases 19, 20; Table 1) with comparably low values, who were discovered early and developed normally under treatment, the third one (case 17; Table 1) received insufficient treatment during the first 2 years. Two other cases in this low

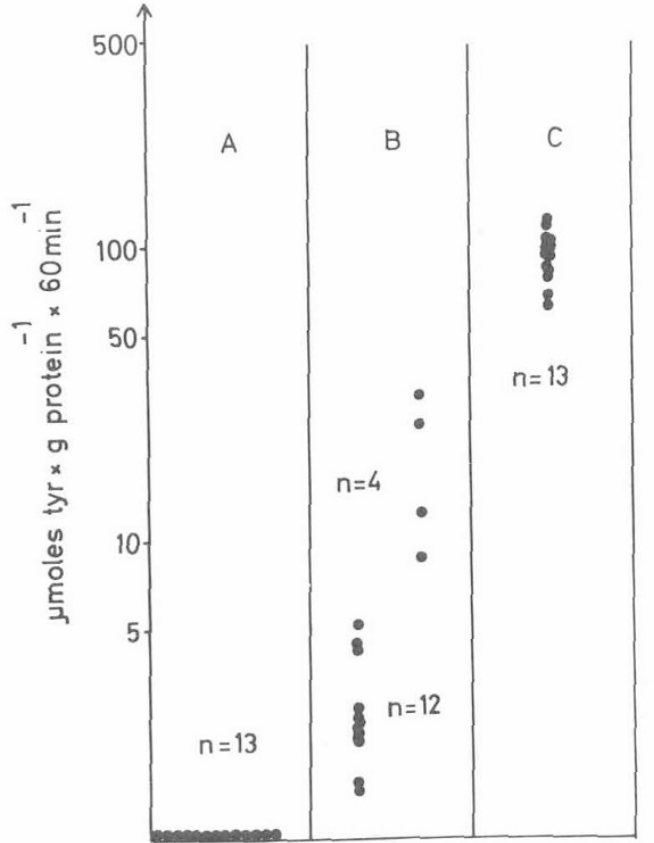

Fig. 3. Phenylalanine hydroxylase activities determined in 42 subjects and subdivided in three groups of value ranges. $A$ : activity not detectable; $B$ : residual activity; $C$ : normal activity (control subjects). tyr: tyrosine.

activity group (cases 16,24) correspond to the clinical diagnosis of hyperphenylalaninemia.

Four cases in group $B$ exhibited higher residual activity, ranging between 8.1 and $32.2 \mu \mathrm{mol}$ tyrosine $/ \mathrm{g}$ protein $\times 60 \mathrm{~min}$. In all of them the diagnosis of hyperphenylalaninemia have already been made by the usual criteria; they are untreated and they have so far reached the normal developmental milestones, being now $2 \frac{1}{2}, 31 \frac{1}{2}$, 2 , and 41/2 years of age (cases 27, 28, 29, 30; Table 1).

One patient (case 26: Table 1) is quite exceptional in showing no correlation whatever between the usual clinical findings and his hydroxylase activity. He was discovered at 2 weeks of age in the neonatal PKU screening program, showed then a phenylalanine blood level of $46 \mathrm{mg} / 100 \mathrm{ml}$ and a biochemical response to phenylalanine loading typical for classic PKU. Despite an early start and a good control of the phenylalanine-restricted diet, the patient developed a severe tetraplegia and seems now, at the age of 12 months, to be mentally retarded. At the ages of 6 weeks and 4 months liver needle biopsies were taken. The hydroxylase determinations showed 75.5 and $55.2 \mu \mathrm{mol}$ tyrosine $/ \mathrm{g}$ protein $\times 60 \mathrm{~min}$, respectively, i.e., low normal values (1).

Even if the clinical picture does not always allow a clear-cut differentiation between patients with no detectable hydroxylase activity and with low residual activity, there should be a difference in their ability to metabolize phenylalanine. The phenylalanine tolerance, i.e., the amount of phenylalanine per $\mathrm{kg}$ body weight in the diet during a long period of well controlled therapy, is two- to threefold higher in patients with low residual activity (Fig. 4) compared with patients with no detectable enzyme activity. Only two patients with low residual activity have an unusually low phenylalanine tolerance (cases 23, and 25). They have been observed for a short time only and may still change their phenylalanine tolerance in future months.

\section{DISCUSSION}

For reasons of standardization we chose for our phenylalanine hydroxylase assay the constant addition of $20-\mu$ l supernatant and a reaction time of $60 \mathrm{~min}$. In principle, the assay could be optimized for high hydroxylase activities using higher phenylalanine concentrations and reducing the reaction time to $20 \mathrm{~min}$. Under such 


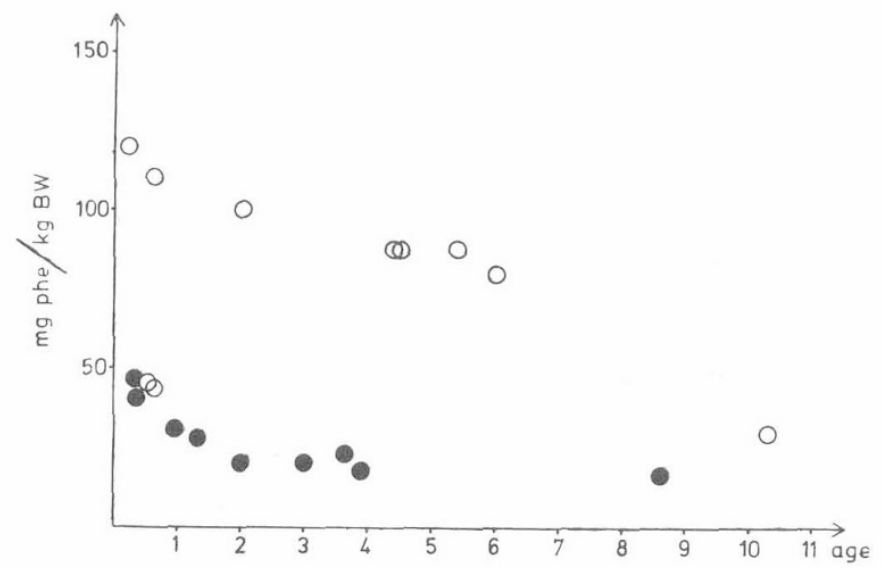

Fig. 4. Phenylalanine tolerance in patients with no detectable enzyme acitivity $(-)$ and with low residual enzyme activity $(O)$. Each circle stands for a single subject. Tolerance is expressed (along ordinate) as the phenylalanine intake in milligrams per $\mathrm{kg}$ body weight $(B W)$ per $24 \mathrm{hr}$ which is tolerated with a normal (or near normal) phenylalanine blood level and a normal gain in weight and height.

conditions, however, the relative amounts of tyrosine formed would be reduced when measuring low residual activities, and other technical problems would be increased. Our assay differs from Kaufman's (11) in so far as we substitute dithioerythritol for the reductase-dependent tetrahydrobiopterin regenerating system. The catalase needed during the reaction is presumed to be present in the crude extract. The use of tetrahydrobiopterin instead of dimethyltetrahydropteridine is a requisite for low activity determinations (see Fig. 2).

In our experience so far no detectable enzyme activity has been correlated consistently with classic PKU except in one instance (case 33; Table 1). The liver biopsy was therefore repeated, with the same result in the assay. That patient was a 3-month-old male. A protein loading test $(180 \mathrm{mg}$ phenylalanine/ $\mathrm{kg}$ body weight for 3 days (2)), did not raise the phenylalanine blood levels beyond $13 \mathrm{mg} / 100 \mathrm{ml}$, suggesting a diagnosis of hyperphenylalaninemia rather than PKU. This was further implied by identical loading test results in a 6-year-old brother, who never received treatment and is apparently healthy. Enzyme determination has not been performed in this boy.

Patients with residual enzyme activities merit further discussion, because their exact classification is difficult. Generally patients with high residual activities have phenylalanine blood levels below $10 \mathrm{mg} / 100 \mathrm{ml}$ on a normal protein intake and are not treated by us. Patients with low residual activity usually are treated; two patients in the lower residual activity group, however, did not receive treatment. Case 22 (Table 1) has been followed by us since her third week of life. She was classified as suffering from mild hyperphenylalaninemia because of phenylalanine blood levels below $10 \mathrm{mg} / 100 \mathrm{ml}$. Phenylalanine loading studies were suggestive of this diagnosis. Case 16 (Table 1) was at the time of the biopsy a 1-year-old girl who received a phenylalanine-restricted diet for approximately 1 year because her phenylalanine blood levels exceeded $10 \mathrm{mg} / 100 \mathrm{ml}$ repeatedly. Her increasing phenylalanine tolerance then suggested that the diet might be discontinued, and so far she is doing well on a normal food intake, her phenylalanine blood level not exceeding $10 \mathrm{mg} / 100 \mathrm{ml}$. Mental development is proceeding normally in both patients at the ages of 1 and 2 years, respectively.

The observation of some, although very little, residual enzyme activity in cases with classic PKU is interesting. One single pertinent case has been described so far (6). We believe that we have demonstrated low residual activity in several PKU patients and wish to cite as examples two pairs of brothers. One boy of each pair (cases 14 and 15 ; Table 1) was born before diets restricted in phenylalanine were available, and these patients had to be institutionalized because of severe mental retardation. The other boy of each pair (cases 19 and 20; Table 1) was detected in the neonatal period, received dietetic treatment, and developed normally. These data suggest that such low residual enzyme activities do not necessarily permit dismissal of the diagnosis of PKU with its therapeutic implications. One could speculate that minimal phenylalanine hydroxylase activity is genetically determined.

The higher residual activity group corresponds to two cases investigated earlier (8) and to the family described by Kang et al. (9) with $31 \%, 10 \%$, and $6 \%$ of normal activity. In comparing data from different laboratories one has to keep in mind that the assays are different, e.g., dimethyltetrahydropteridine or tetrahydrobiopterin may be used. As might be anticipated, high residual activity has been found in cases of hyperphenylalaninemia. Our case with practically normal activity despite other biochemical signs of classic PKU is presently being investigated. It is likely that this child suffers from a different molecular defect. Phenylalanine hydroxylase is part of a multienzyme system, so that other defects in this complex system could be anticipated. The large range of hydroxylase rest activities may be compared with the well known molecular genetic variability in galactose-1-phosphate uridyltransferase in galactosemia (3) and glucose-6-phosphate dehydrogenase deficiency (4).

\section{SUMMARY}

Using a microenzyme assay on liver needle biopsy specimens, several ranges of phenylalanine hydroxylase activity were found in patients with PKU and hyperphenylalaninemia. No detectable activity is primarily associated with classic PKU. Low residual activities are not uniformly correlated with PKU or hyperphenylalaninemia. Patients with residual activities of more than $10 \%$ of normal seem to have a sufficient phenylalanine tolerance not to be in need of a phenylalanine-restricted diet.

\section{REFERENCES AND NOTES}

1. Bartholomé, K: A new molecular defect in phenylketonuria. Lancet, ii: 1580 (1974).

2. Blaskovics, M.: Phenylketonuria and other phenylalaninaemias. In: H. Bickel: Clinics in Endocrinology and Metabolism, Vol. 3, p. 87 (W. B. Saunders. Philadelphia, 1974)

3. Beutler, E., Baluda, M. C., Sturgeon, P., and Day, R. W.: The genetics of galactose-1-phosphate uridyltransferase deficiency. J. Lab. Clin. Med., 68: 646 (1966).

4. Beutler, E. Glucose-6-phosphate-dehydrogenase deficiency, In: J B. Stanbury, J. B. Wyngaarden, and O.S. Fredrickson: The Metabolic Basis of Inherited Disease, Ed. 3, p. 1364, (McGraw-Hill Book Co., New York, 1972).

5. Fisher, D. B., and Kaufman, S.: The stimulation of rat liver phenylalanine hydroxylase by lysolecithin and $\alpha$-chymotrypsin. J. Biol. Chem., 248: 4345 (1973).

6. Friedman, P. A., Fisher D. B., Kang. E. S., and Kaufman, S.: Detection of hepatic phenylalanine-4-hydroxylase in classical phenylketonuria. Proc. Nat. Acad, Sci. U. S. A., 70: 552 (1973)

7. Jervis, G. A.: Phenylpyruvic oligophrenia deficiency of phenylalanine-oxidizing system. Proc. Soc. Exp. Biol., 82: 574 (1953).

8. Justice, P., O'Flynn, M. E., and Hsia, D. Y. Y.: Phenylalanine-hydroxylase activity in hyperphenylalaninemia. Lancet, $i: 928$ (1967).

9. Kang, E. S., Kaufman, S., and Gerald, P. S.: Clinical and biochemical observations of patients with atypical phenylketonuria. Pediatrics, 45:83 (1970).

10. Kaufman, S.: The enzymatic conversion of phenylalanine to tyrosine. J. Biol. Chem., 226: 511 (1957).

11. Kaufman, S.: Phenylalanine hydroxylase of human liver: Assay and some properties. Arch. Biol. Biophs., 134: 249 (1969).

12. Kaufman, $\mathbf{S}$.: The phenylalanine hydroxylating system from mammalian liver. Advan. Enzymol. Relat. Areas Mol. Biol., 35: 245 (197I).

13. La Du, B. N., and Zannoni, V. G.: Basic biochemical disturbance in aromatic amino acid metabolism in phenylketonuria. In: H. Bickel, F. P. Hudson, and L. I. Woolf: Phenylketonuria, p. 6 (G. Thieme Verlag, Stuttgart, 1971)

14. Lowry, O. H., Rosebrough, N. J., Farr, A. L., and Randall, R. J.: Protein measurement with the Folin phenol reagent. J. Biol. Chem., 139: 265 (1951).

15. Milstien, S., and Kaufman, S.: Personal communication.

16. Udenfriend, S., and Cooper, J. R.: The enzymatic conversion of phenylalanine to tyrosine. J. Biol. Chem., 194: 503 (1952).

17. Zinsser, Frankfurt, Germany.

18. Classical PKU is characterized by Folling's syndrome of an extremely elevated serum phenylalanine level, a special pattern of metabolites in the urine, and severe mental retardation if the metabolic condition is not treated. Hyper- 
phenylalaninemia imitates the metabolic condition at a lower level but will not, even if untreated, cause mental retardation

19. The authors gratefully acknowledge the technical assistance of Miss Erika Grube, and are indebted to Dr. Hildgund Schmidt for much help during the investigation.
20. This work was supported by the Deutsche Forschungsgemeinschaft (SFB 35).

21. Requests for reprints should be addressed to: Klaus Bartholomé, M.D., 6900 Heidelberg, Universitäts-Kinderklinik, Im Neuenheimer Feld 150, Federal Republic of Germany.

22. Accepted for publication July 25, 1975
Bilirubin mitochondria ligandin oxidative phosphorylation

\title{
Ligandin Reverses Bilirubin Inhibition of Liver Mitochondrial Respiration in Vitro
}

\author{
KAZUAKI KAMISAKA, ZENAIDA GATMAITAN, CYRIL L. MOORE, AND \\ IRWIN M. ARIAS(17) \\ The Liver Research Center, Division of Gastroenterology-Liver Diseases, Department of Medicine and Department \\ of Neurology. Albert Einstein College of Medicine, Bronx. New York. USA
}

\section{Extract}

Ligandin, an abundant cytoplasmic binding protein of bilirubin and other ligands in liver cells, completely prevented the inhibitory effect of bilirubin on respiration and oxidative phosphorylation by isolated rat liver mitochondria. At equimolar concentrations of bilirubin and ligandin or human serum albumin, mitochondrial respiration was fully restored to control values. At greater ratios of bilirubin and ligandin or human serum albumin, the latter had a stronger protective effect. These studies suggest that ligandin may have a physiologic role in protecting mitochondrial systems against bilirubin toxicity.

\section{Speculation}

Some organs, such as liver, kidney, and intestine, transport various organic anions such as bilirubin and possess a soluble binding protein (ligandin) for protection of intracellular organelles. Other organs, such as the brain, lack this protective mechanism and, therefore, are more susceptible to toxicity as, for example, from bilirubin (kernicterus).

Unconjugated bilirubin produces toxic effects on mitochondrial electron transport, oxidative phosphorylation, and ultrastructure (I, II). Respiratory stimulation and uncoupling are observed at concentrations lower than those necessary to inhibit oxidative phosphorylation (I, II). Bovine or human serum albumin in vitro prevents injurious effects of bilirubin on isolated mitochondria by preferentially binding the bile pigment (10).

Ligandin is an abundant cytoplasmic protein found in parenchymal liver cells, proximal tubules of the kidney, and intestinal mucosa, and binds bilirubin and other ligands. Ligandin is postulated to be an important determinant in the transport of various endogenous and exogenous organic anions $(5,7)$.

We have studied the role of ligandin in protecting rat liver mitochondria against effects of bilirubin on respiration and oxidative phosphorylation.

\section{METHODS}

Crystalline bilirubin was obtained from Eastman Kodak (12) (E $=60 \times 10^{3}$ at $450 \mathrm{~nm}$ in chloroform), recrystallized, and stored at $0^{\circ}$ in the dark. Bilirubin solutions were freshly prepared at concentrations of $10^{-3}-10^{-4} \mathrm{M}, 0.02 \mathrm{M}$ aqueous $\mathrm{NaOH}$, and kept at $0^{\circ}$ in the dark. Human serum albumin (fraction $\mathrm{V}$, defatted) was obtained from Sigma (13) and prepared in solution at concentrations of $10^{-3}-10^{-4} \mathrm{M}$

Ligandin was purified from Sprague-Dawley rats as described previously (6). Livers were rapidly removed from male rats $(250-350 \mathrm{~g})$ after decapitation and placed in medium containing $0.25 \mathrm{M}$ sucrose, $1.0 \mathrm{mM}$ EDTA, and $10.0 \mathrm{mM}$ Tris- $\mathrm{HCl}, \mathrm{pH} 7.4$. The tissue was homogenized with approximately 4 volumes medium using a Potter-Elvehjem glass homogenizer. The homogenate was centrifuged at $800 \times g$ and the supernatant was centrifuged at $13,000 \times \mathrm{g}$. The crude mitochondrial pellet was washed twice in $0.25 \mathrm{M}$ sucrose containing $10 \mathrm{mM}$ Tris- $\mathrm{HCl}, \mathrm{pH}$ 7.4. Resuspended mitochondria were collected by centrifugation at $25,000 \times g$. All procedures were performed at $4^{\circ}$.

Respiration was studied polarographically using a Clarke oxygen electrode (14) and a specially designed chamber with a column of $1.5 \mathrm{ml}$. The respiration medium consisted of $0.25 \mathrm{M}$ sucrose, $5 \mathrm{mM} \mathrm{MgCl}_{2}, 20 \mathrm{mM}$ potassium phosphate, $10 \mathrm{mM}$ Tris- $\mathrm{HCl}, \mathrm{pH} 7.4(8)$

\section{RESULTS}

Addition of less than $20-30 \mu \mathrm{m}$ of bilirubin to the mitochondrial medium containing glutamate-malate as a substrate pair increased basal respiration (state 4 rate), increased phosphorylating respiration (state 3 rate), and, as shown in Figure 1, decreased the respiratory control index (state 3:4). At higher concentrations of bilirubin, a major decrease of state 3 respiration was observed.

In the presence of human serum albumin, bilirubin effects on state 3 and 4 respiration were reversed (Fig. 2). At an equimolar ratio of bilirubin and human serum albumin, the inhibitory effect of bilirubin almost disappeared. As the bilirubin concentration increased, the inhibitory effect of albumin was decreased but was 